\title{
Optimal Capital-Gains Taxation Under Limited Information
}

\section{Citation}

Green, Jerry, and Eytan Sheshinski. 1978. Optimal capital-gains taxation under limited information. Journal of Political Economy 86, no. 6: 1143-1158.

\section{Published Version}

http://dx.doi.org/10.1086/260732

\section{Permanent link}

http://nrs.harvard.edu/urn-3:HUL.InstRepos:3210340

\section{Terms of Use}

This article was downloaded from Harvard University's DASH repository, and is made available under the terms and conditions applicable to Other Posted Material, as set forth at http:// nrs.harvard.edu/urn-3:HUL.InstRepos:dash.current.terms-of-use\#LAA

\section{Share Your Story}

The Harvard community has made this article openly available.

Please share how this access benefits you. Submit a story.

Accessibility 


\title{
Optimal Capital-Gains Taxation under Limited Information
}

\section{Jerry R. Green}

Harvard Universily

\section{Eytan Sheshinski}

Hebrew University of Jerusalem

\begin{abstract}
Taxation of capital gains at realization may distort individuals' decisions regarding holding or selling during an asset's lifetime. This creates the problem of designing a tax structure for capital gains so as to induce efficient patterns of holding and selling. Several tax structures are explored in this paper. Linear taxation, at rates which rise with the holding period, can achieve the first best, even under the conditions of limited information that we postulate. The form of the optimal tax is independent of the stochastic structure of rates of return. We also derive the optimal nonlinear tax under the constraint that it be independent of the holding period. Second-best tax rules are examined. Results in a two-period model are contrasted with those in a continuous time framework. Also treated is the case in which the returns to the asset under consideration depend on the aggregate quantity invested.
\end{abstract}

\section{Introduction}

This paper is addressed to the problem of the optimal design of a tax system for capital gains when the taxing authority has only a limited degree of information. We assume that the only variables observable for tax purposes are the amount of the realized capital gain and the length of time over which it has accrued. In particular, if an asset is sold at some moment in time, taxes cannot be based on direct observation of either the gain that would have been realized had it been sold earlier or the expected returns that were foregone by not holding it into the future, both of which are pieces of information in the private domain of the investor.

This work was supported by National Science Foundation grants SOC71-03803 and APR77-06999 at Harvard University and SOC77-06000 at the Institute for Mathematical Studies in the Social Sciences, Stanford University. 
This framework is natural for many considerations involving capitalgains taxation. Taxes are levied upon realization of the gain, and the date of realization is under the control of the investor. Accrual-based taxation, although potentially usable for widely traded assets (securities) whose market price can be determined retrospectively, is nevertheless not a viable policy option at present. For businesses, real estate, and other thinly traded capital assets, realization taxes are clearly the only feasible alternative. For these reasons, in this paper we have concentrated exclusively on the realization base.

It is well known that all forms of capital-income taxation involve some type of intertemporal distortion. For example, the taxation of interest biases consumption toward earlier periods vis-à-vis the optimum. This is a problem with capital-gains taxation as well, but one which is conceptually distinct from the misallocation of resources due to mistakes in continuing or terminating certain investments.

In this paper we assume that there are two types of assets. One is subject to capital-gains taxation and has a duration of either one or two periods, at the discretion of the investor. The other is an asset with a duration of one period which earns a fixed return. In order to dissociate the two types of inefficiencies mentioned above, we will assume that both the government's and the investor's objective functions are to maximize the expected value of wealth at the end of the second period. This removes both considerations of differences in risk aversion and in intertemporal preferences.

We will assume that the asset subject to capital-gains taxation earns a variable rate of return. If this return were not risky, the rate of taxation could be fixed ex ante at the same level as that on the alternative asset. Therefore some variation is necessary in order to make the problem nontrivial. Further, suppose that at the end of the first period the investor and the government always had identical expectations concerning the secondperiod rate of return. In this case as well, private and social objectives would coincide if the effective rate of taxation on second-period gains were equated to that on the alternative asset. The problem of efficiency in capital-gains taxation is therefore relevant only in a context in which investors' prospective, as well as retrospective, information is superior to the government's. In this world, the government's attempt to control the agent's decision regarding continuation or termination of the project may be complicated by the tax advantages perceived by individuals in light of the resolution of both the first and second periods' uncertainties.

For many types of assets, and for securities in particular, efficientmarkets theory tells us that the economic agent and the tax authority should be equally ignorant about future returns. However, it is precisely the thinly traded, relatively inhomogeneous assets that allow learning by the owner beyond what one could discover as an outside observer. These 
are just those for which realization taxation is most relevant. Therefore, the reader skeptical about both the possibility of investor forecasting and the impossibility of accrual taxation should keep this type of asset in mind. We believe, however, that the basic principles illustrated by our analysis are of more general applicability.

Section II treats the basic two-period model. General tax policies are described. It is shown that by making taxes linear in the capital gain at rates that differ for one- and two-period holdings, appropriate incentives are created to make individuals follow the socially most productive investment rules. This tax function can be specified without knowledge of the joint distribution of returns in the two periods. We compare this scheme to one in which capital gains are imputed to each period within the holding period at a uniform rate and linear taxes are applied to each date separately, with an interest penalty being added to taxes unpaid at earlier dates. This is related to the cumulative-averaging method proposed by Vickrey (1947, app. 3, pp. 417-24) and discussed by David (1968, pp. 185-89). We show that the rate of interest on back taxes implicit in the optimal linear tax scheme necessarily exceeds twice the net rate of return on alternative assets. Moreover, we demonstrate that no cumulativeaveraging rule can exactly attain the first best, in general.

Section II goes on to consider tax policies that are allowed to be nonlinear in the size of the gain, but which must be independent of the length of the holding period. We show that there exists a family of tax policies of this form capable of decentralizing the first best and that these are progressive in the size of the gain. Finally, a second-best linear, timeindependent rule is derived.

Section III considers a continuous time version of this model. In a particular example we explore the two successful tax rules of Section II. The results are somewhat different: There are no fully optimal linear, time-dependent rules, and, although optimal nonlinear rules exist, they seem to be regressive rather than progressive in the gain. This points out the need for further work on capital-gains taxation in multiperiod models.

In Section IV we consider the case in which the rate of return to holding the risky asset varies with the intensity of investment in this form. Assuming that the variance of returns is small, we show that at the social optimum there will be a private bias in favor of the risky asset. On the other hand, at the second best with uniform taxation, there is a bias in favor of the alternative asset.

\section{Two-Period Model}

Here our analysis centers on investor behavior regarding a risky asset whose potential lifetime is two periods. When such an investment is 
initiated, the returns in each of these periods are viewed as a random variable, $r_{1}$ in the first period and $r_{2}$ in the second. We concentrate on the decision to be made after one period has elapsed. The investor must determine whether to continue this project or to switch to an alternative, safe asset with a return $R$ per period.

There are two essential features of our model of an informational nature. Having held the asset for one period, the investor has acquired some information about its second-period return. We assume, for simplicity, that at this stage $r_{2}$ is known to him with certainty. The second aspect relates to the tax treatment of these capital gains and the information available to the government on which these taxes can be based. If the asset is terminated, the government observes the realized gain $r_{1}$ but does not learn the value of $r_{2}$ that was foregone by the investor's sale. If the investment is continued, the government observes only the total twoperiod return, $\left(1+r_{1}\right)\left(1+r_{2}\right)-1$, per unit invested but cannot identify $r_{1}$ and $r_{2}$. Returns to holding the safe asset are taxed at a proportional rate $t$.

Because of the informational structure of the market, the taxes can depend on the length of the holding period and on the observed return in an arbitrary way but cannot be functions of other variables.

Let

$$
\begin{aligned}
& \tau\left(1, r_{1}\right)=\begin{array}{c}
\text { taxes paid on risky assets sold after one period, } \\
\text { having earned } r_{1}
\end{array} \\
& \tau\left(2,\left(1+r_{1}\right)\left(1+r_{2}\right)-1\right)=\text { taxes paid on risky assets } \\
& \text { sold after two periods, having earned } \\
& \left(1+r_{1}\right)\left(1+r_{2}\right)-1 .
\end{aligned}
$$

Consider an investor whose known pattern of returns is $r_{1}, r_{2}$. He will hold the asset for the second period if

$$
\begin{aligned}
\left(1+r_{1}\right)\left(1+r_{2}\right) & -\tau\left(2,\left(1+r_{1}\right)\left(1+r_{2}\right)-1\right) \\
& >\left[\left(1+r_{1}\right)-\tau\left(1, r_{1}\right)\right][1+R(1-t)]
\end{aligned}
$$

and will sell it if the inequality is reversed.

For a given tax policy and a first-period return $r_{1}$, the level of $r_{2}$ at which the individual is indifferent between holding and selling, $\dot{r}_{2}\left(r_{1}\right)$, is thus given by

$$
\begin{aligned}
\left(1+r_{1}\right)\left[1+\hat{r}_{2}\left(r_{1}\right)\right] & -\tau\left(2,\left(1+r_{1}\right)\left[1+\hat{r}_{2}\left(r_{1}\right)\right]-1\right) \\
& =\left[\left(1+r_{1}\right)-\tau\left(1, r_{1}\right)\right][1+R(1-t)] .
\end{aligned}
$$

In order to dissociate the problems inherent in capital-gains taxation from the distortions of interest-income taxation more generally, we consider the social objective of maximizing the expected total return at the end of the second period per unit invested. The government's policy 
instrument is the system of capital-gains taxes, $\tau(\cdot, \cdot)$. The rate of taxation on the safe asset $t$ is taken as given.

Let $f\left(r_{1}, r_{2}\right)$ be the density function of the random returns $\left(r_{1}, r_{2}\right)$. The expected total return per unit invested in the risky asset is given by

$$
\begin{aligned}
\int_{r_{1}} \int_{r_{2}>r_{2}\left(r_{1}\right)} & \left(1+r_{1}\right)\left(1+r_{2}\right) f\left(r_{1}, r_{2}\right) d r_{2} d r_{1} \\
& +\int_{r_{1}} \int_{r_{2}<r_{2}\left(r_{1}\right)}\left(1+r_{1}\right)(1+R) f\left(r_{1}, r_{2}\right) d r_{2} d r_{1} .
\end{aligned}
$$

The effect of the policy on capital-gains taxation is through its influence on $f(\cdot)$. If a system of taxation can be designed so that

$$
\hat{r}_{2}\left(r_{1}\right) \equiv R,
$$

then a first best is attained at the expected returns

$$
\int_{r_{1}} \int_{r_{2}}\left(1+r_{1}\right)\left[1+\max \left(r_{1}, R\right)\right] f\left(r_{1}, r_{2}\right) d r_{2} d r_{1} .
$$

Clearly, if $t=0$, then by setting $\tau(\cdot, \cdot) \equiv 0$ the individual's problem coincides precisely with the social objective, and $\hat{r}_{2}\left(r_{1}\right) \equiv R$ as can be seen from (3). The problem of optimal capital-gains taxation, as we have posed it, depends on the fact that the taxation of returns on the safe asset might result in a "lock-in" type of effect. The individual, by postponing the realization of his gain, may be able to alter the extent of his tax liability. Since this will depend on the gain he has made in the first period, the holding function $\dot{r}_{2}\left(r_{1}\right)$ may not be constant, and the first best may be precluded.

\section{Parametrization of Tax Systems}

In general, the government's problem is to select functions $\tau(1, \cdot)$ and $\tau(2, \cdot)$, which may in principle be arbitrary functions of their arguments. Clearly, with this degree of flexibility (3) can be satisfied at $\hat{r}_{2}\left(r_{1}\right) \equiv R$. For practical reasons, however, it may be necessary to restrict the choice of tax functions to some more narrow parametric class.

At one extreme we may consider linear capital-gains taxes that are independent of the holding period. For any such rule $\hat{r}_{2}\left(r_{1}\right)$ will be a decreasing function of $r_{1}$. In fact, if the proportional rate of taxation is $t^{\prime}$, then

$$
\dot{r}_{2}\left(r_{1}\right)=\frac{1+r_{1}\left(1-t^{\prime}\right)}{\left(1+r_{1}\right)\left(1-t^{\prime}\right)} R(1-t) .
$$

Because (7) is decreasing in $r_{1}$, the first-best condition $\hat{r}_{2}\left(r_{1}\right) \equiv R$ cannot be satisfied. Individuals with large $r_{1}$ will be locked in. 
To avoid this effect, more complicated parameterizations have been proposed. One possibility is a pair of linear rules but with different rates for different holding periods. Another idea is to overcome the benefit of a potential lock in by charging interest on the taxes that were postponed but would have been due under an accrual-based tax. This embodies the idea of taxing gains differently according to the holding period, but it is not equivalent to any linear rule. Instead of using a tax system that is linear in the capital gain, at a rate that varies with the holding period, one may consider nonlinear taxation at rates that are independent of the length of time the asset is held.

In this section the ability of these alternative rules to achieve efficient outcomes is studied. We first show that linear taxation at variable rates can attain the first-best solution. The interest-rate rule, which is a special form of nonlinear taxation, not independent of the holding period, turns out to be incapable of decentralizing the efficient resource allocation. Allowing general nonlinear taxation at fixed rates, we see that there are many ways of attaining the first best.

The structure of the optimal taxes in the two successful parameterizations is characterized. Later sections deal with second-best taxation under those systems not capable of achieving full efficiency.

\section{Linear Taxation at Rates Dependent on Holding Period}

Proposition 1.-The pair of linear capital-gains tax functions

$$
\begin{aligned}
& \tau\left(1, r_{1}\right)=\frac{r_{1} t}{1+R(1-t)}, \\
& \tau\left(2,\left(1+r_{1}\right)\left(1+r_{2}\right)-1\right)=\left[\left(1+r_{1}\right)\left(1+r_{2}\right)-1\right] \iota
\end{aligned}
$$

achieves the first best.

Proof.-We must show from (3) that

$$
\begin{aligned}
\left(1+r_{1}\right)\left(1+r_{2}\right)- & {\left[\left(1+r_{1}\right)\left(1+r_{2}\right)-1\right] t } \\
> & {\left[1+r_{1}-\frac{r_{1} t}{1+R(1-t)}\right][1+R(1-1)] }
\end{aligned}
$$

if and only if $r_{2}>R$. Rewriting (9) we obtain $r_{2}>R$ directly, independently of the value of $r_{1}$, and the converse follows by a similar computation. (Q.E.D.)

\section{Linear Rules with Interest on Deferred Taxes}

We now consider the policy of charging interest on deferred taxes. The first problem to be surmounted is that under the informational restrictions we have imposed, the government cannot determine how much of the 
realized two-period gains were actually earned in the first period. This would be necessary to determine the amount of the interest payments. A natural assumption, and one commonly suggested in the capital-gainstaxation literature, is that the gains accrued at a uniform rate over the two periods. That is, if the terminal value of the asset at the end of two periods is $\left(1+r_{1}\right)\left(1+r_{2}\right)$ per unit invested, then it is presumed that the rate of gain in each period was

$$
\left(\mathrm{I}+r_{1}\right)^{1 / 2}\left(1+r_{2}\right)^{1 / 2}-1 .
$$

Taxes are computed as follows: One-period gains are taxed at the linear schedule

$$
\tau\left(1, r_{1}\right)=t_{1} r_{1}
$$

as in the previous case. Two-period gains are also taxed at the rate $t_{1}$ but, in addition, the implicit gains at the rate $\left(1+r_{1}\right)^{1 / 2}\left(1+r_{2}\right)^{1 / 2}-1$, on which taxes were not paid after one period, bear an interest penalty of $\rho$. Thus,

$$
\begin{aligned}
\tau(2, & \left.\left(1+r_{1}\right)\left(1+r_{2}\right)-1\right) \\
= & t_{1}\left((1+\rho)\left[\left(1+r_{1}\right)^{1 / 2}\left(1+r_{2}\right)^{1 / 2} \quad 1\right]\right. \\
& +\left\{\left(1+r_{1}\right)^{1 / 2}\left(1+r_{2}\right)^{1 / 2}-t_{1}\left[\left(1+r_{1}\right)^{1 / 2}\left(1+r_{2}\right)^{1 / 2}-1\right]\right\} \\
& \left.\cdot\left[\left(1+r_{1}\right)^{1 / 2}\left(1+r_{2}\right)^{1 / 2}-1\right]\right) .
\end{aligned}
$$

The first term on the right-hand side represents the principal and interest on taxes due to the imputed first-period gains. The second term is the product of the imputed net of tax wealth at the end of the first period and the assumed rate of gain in the second period.

Proposition 2.-The system of capital-gains tax functions given by (11) and (12) cannot achieve the first best, for any choice of the parameters $t_{1}, \rho$.

Proof.-We will proceed by writing the first-best condition $\hat{r}_{2}\left(r_{1}\right) \equiv R$ as a function of the parameters $t_{1}, \rho$. Then we take the Taylor expansion in $r_{1}$ of this identity. If it is to be satisfied for all $r_{1}$, all the coefficients, which are functions of $t_{1}$ and $\rho$, must be zero. We will obtain a contradiction to this system of requirements. Writing the condition for $\hat{r}_{2}\left(r_{1}\right)$ under the tax formulas (11) and (12), we have

$$
\begin{aligned}
(1 & \left.+r_{1}\right)\left(1+\hat{r}_{2}\right)-t_{1}\left((1+\rho)\left[\left(1+r_{1}\right)^{1 / 2}\left(1+\hat{r}_{2}\right)^{1 / 2}-1\right]\right. \\
& +\left\{\left(1+r_{1}\right)^{1 / 2}\left(1+\hat{r}_{2}\right)^{1 / 2}-t_{1}\left[\left(1+r_{1}\right)^{1 / 2}\left(1+\hat{r}_{2}\right)^{1 / 2}-1\right]\right\} \\
& \left.\cdot\left[\left(1+r_{1}\right)^{1 / 2}\left(1+\hat{r}_{2}\right)^{1 / 2}-1\right]\right) \\
& =\left[1+r_{1}\left(1-t_{1}\right)\right][1+R(1-t)] .
\end{aligned}
$$

This can be rewritten at $r_{2}=R$ as

$$
\begin{array}{r}
0=-R t\left(1+r_{1}\right)+r_{1} R t_{1} t+\rho t_{1}\left[\left(1+r_{1}\right)^{1 / 2}(1+R)^{1 / 2}-1\right] \\
+t_{1}\left\{(1+R)-t_{1}\left[\left(1+r_{1}\right)^{1 / 2}(1+R)^{1 / 2}-1\right]^{2}\right\} .
\end{array}
$$


If (14) is satisfied for all $r_{1}$, then all the coefficients of its Taylor expansion around $r_{1}=0$ must be zero. The first three of these coefficients are:

$$
\begin{gathered}
r_{1}^{0}:-R t+\rho t_{1}\left[(1+R)^{1 / 2}-1\right] \\
+t_{1}(1+R)-t_{1}^{2}\left[(1+R)^{1 / 2}-1\right]^{2} \\
r_{1}^{1}:-R t\left(1-t_{1}\right)+\frac{\rho t_{1}}{2}(1+R)^{1 / 2}-t_{1}^{2}\left[(1+R)-(1+R)^{1 / 2}\right] \\
r_{1}^{2}:-\frac{\rho t_{1}}{4}(1+R)^{1 / 2}-\frac{t_{1}^{2}}{2}(1+R)^{1 / 2} .
\end{gathered}
$$

Solving (17), we have

$$
-\rho=2 t_{1} .
$$

Substituting (18) into the conditions that (15) and (16) be zero, we obtain

$$
\begin{aligned}
& 0=-R t+t_{1}(1+R)-t_{1}^{2} R \\
& 0=-R t\left(1-t_{1}\right)-t_{1}^{2}(1+R) .
\end{aligned}
$$

We will now show that $t_{1}$ cannot solve (19) and (20) simultaneously whenever $0<t \leqq 1$ and $R>0$.

Multiplying (19) by $(1+R)$ and (20) by $R$ and subtracting the result, we have

$$
t_{1}=\frac{R t}{(1+R)^{2}-R^{2} t} .
$$

Substituting (21) into (19) and simplifying, we reduce the condition for existence of a solution to the requirement

$$
0=(1-t)^{2} R^{4}+5(1-t) R^{3}+(9-4 t) R^{2}+7 R+2,
$$

which is obviously a contradiction. (Q.E.D.)

Although this proposition proves that the first-best policy cannot be attained by an interest-penalty formula, we know that the optimal linear taxes, which can achieve the first best, are increasing in the holding period. There is a type of interest-penalty formula embedded in the firstbest tax rules, but the implicit interest rate depends on the size of the capital gain. Because this type of capital-gains taxation formula is frequently suggested to overcome the lock-in effect, it is of interest to ascertain the approximate magnitude of the rates implied by the first-best linear rule. One might think that the interest penalty should be at the net rate of return available to investors on the alternative asset. In this way they would be indifferent between paying the tax and holding the alter- 
native asset for one period or retaining the risky asset for the remainder of its life. This is not correct.

Let us define implicit interest penalty $\rho$ as that rate which equates tax revenue using the optimal two-period linear rate implicit in (8), with the revenue generated by using the optimal one-period rate in each period separately and adding a fraction $\rho$ of the taxes that were due but deferred at the end of the first period. Thus $\rho$ is given by

$$
\begin{aligned}
t\left[\left(1+r_{1}\right)\left(1+r_{2}\right)-1\right] & =\frac{(1+\rho) t}{1+R(1-t)}\left[\left(1+r_{1}\right)^{1 / 2}\left(1+r_{2}\right)^{1 / 2}-1\right] \\
& +\frac{t}{1+R(1-t)}\left[\left(1+r_{1}\right)^{1 / 2}\left(1+r_{2}\right)^{1 / 2}-1\right] \\
& \cdot\left\{\left(1+r_{1}\right)^{1 / 2}\left(1+r_{2}\right)^{1 / 2}-\frac{t}{1+R(1-t)}\right. \\
& \left.\cdot\left[\left(1+r_{1}\right)^{1 / 2}\left(1+r_{2}\right)^{1 / 2}-1\right]\right\} .
\end{aligned}
$$

Proposition 3.-If $r_{1}$ and $r_{2}$ are nonnegative with probability one, the implicit interest rate is at least twice the net rate of return on the safe asset.

Proof.-Equation (23) may be simplified to give $\rho$ as a function of $r_{1}$ and $r_{2}$ :

$$
\begin{aligned}
\rho=R(1-t)[(1 & \left.\left.+r_{1}\right)^{1 / 2}\left(1+r_{2}\right)^{1 / 2}+1\right] \\
& +\frac{t}{1+R(1-t)}\left[\left(1+r_{1}\right)^{1 / 2}\left(1+r_{2}\right)^{1 / 2}-1\right] .
\end{aligned}
$$

Whenever $r_{1}$ and $r_{2}$ are nonnegative,

$$
\rho \geqq 2 R(1-t) \text {. (Q.E.D.) }
$$

Thus if the government were to use the net rate of return $R(1-t)$ as an interest charge applied to previously accrued taxes, the resulting system would tax two-period holdings at too low a rate relative to oneperiod holdings, and the lock-in effect would not be overcome.

\section{Nonlinear Taxation Independent of Holding Period}

We now consider the case of general nonlinear taxation according to a schedule that is constrained to be independent of the holding period. The tax liability is written $\tau(x)$, where $x$ is the capital gain. (This specializes the formulation of $[1]$ to require $\tau[1, x]=\tau[2, x]$, for all $x$.) 
Let us suppose that the first-period return is $r_{1}$. If $\tau(\cdot)$ induces an efficient pattern of resource allocation, we can see from (2) that it must satisfy

$$
\begin{aligned}
& \tau\left(\left(1+r_{1}\right)\left(1+r_{2}\right)-1\right) \leqq \\
&-\left[1+r_{1}\right)\left(1+r_{2}\right) \\
&-\left[1+r_{1}-\tau\left(r_{1}\right)\right][1+R(1-t)],
\end{aligned}
$$

as $r_{2} R$, for all $r_{1}$. We will show that there is a family of functions $\tau(\cdot)$ satisfying condition (26).

Proposition 4.-Assuming that $\tau(0)=0$, there exists a family of tax functions $\tau(\cdot)$, generating an efficient pattern of holding for the capital asset.

Proof.-We will proceed constructively, defining such a family and then showing that it satisfies (26). Let us define a sequence

$$
x_{i}=(1+R)^{i}-1 \quad i=0,1, \ldots
$$

Rewriting (26) for $r_{2}=R$, we have

$$
\begin{aligned}
\tau\left(\left(1+r_{1}\right)\right. & (1+R)-1) \\
& =\left(1+r_{1}\right)(1+R)-\left[1+r_{1}-\tau\left(r_{1}\right)\right][1+R(1-\iota)]
\end{aligned}
$$

for all $r_{1}$. Taking $r_{1}=0=x_{0},(28)$ gives

$$
\tau(R)=\iota R=\tau\left(x_{1}\right) .
$$

Proceeding iteratively, we can define $\tau\left(x_{i}\right)$ for all $i$ by

$$
\tau\left(x_{i}\right)=t R \sum_{j=0}^{i-1}(1+R)^{j}[1+R(1-t)]^{i-j-1} .
$$

Consider a candidate for an optimal tax function defined on the interval $(0, R)$ satisfying $\tau(0)=0, \tau(R)=t R$. Choosing any point $y_{0} \in(0, R)$ we can follow the same procedure to construct $\tau\left(y_{1}\right)$ at $y_{1}=(1+R) y_{0}$ $+R$, since by (28)

$$
\tau\left(y_{1}\right)=(1+R) y_{0}+R t-\left[y_{0}-\tau\left(y_{0}\right)\right][1+R(1-t)] .
$$

Thus we have constructed $\tau(\cdot)$ on the interval $\left[R,(1+R)^{2}-1\right]$ $\left[=\left(x_{1}, x_{2}\right)\right]$. This procedure can be continued. Therefore, by fixing $\tau(\cdot)$ on $(0, R)$ we determine it completely.

We will now show that any function $\tau(\cdot)$ generated by a function on $(0, R)$ satisfying

$$
\begin{aligned}
& 0<\tau^{\prime}(x)<1 \\
& \tau(0)=0, \quad \tau(R)=t R
\end{aligned}
$$

will be compatible with (26), and is therefore an optimal tax schedule. 
Let us begin with a point $y_{1} \in\left[R,(1+R)^{2}-1\right]$. This point is generated by $y_{0} \in(0, R)$ given by

$$
y_{0}=\frac{y_{1}-R}{1+R} .
$$

Using (31),

$$
\tau\left(y_{1}\right)=y_{1}-R(1-t)-\left[\frac{y_{1}-R}{1+R}-\tau\left(\frac{y_{1}-R}{1+R}\right)\right][1+R(1-t)] .
$$

To show that the value of $\tau\left(y_{1}\right)$ given by (34) is compatible with all of the upper bounds generated by (26) when $r_{2}>R$ and $y_{1}=\left(1+r_{1}\right)\left(1+r_{2}\right)$ -1 , we let $y<y_{0}$. Applying (26) to $y=r_{1}, y_{1}=\left(1+r_{1}\right)\left(1+r_{2}\right)-1$, we have

$$
\tau\left(y_{1}\right)<(1+y)\left(1+r_{2}\right)-[1+y-\tau(y)][1+R(1-t)]
$$

or

$$
\tau\left(y_{1}\right)<y_{1}+1-[1+y-\tau(y)][1+R(1-t)] .
$$

Using (32), the right-hand side of (35) is decreasing in $y$ and equals the right-hand side of (34) for $y=y_{0}=\left(y_{1}-R\right) /(1+R)$. Therefore for $y<y_{0}$, (35) is surely satisfied.

For $y>y_{0}$, (26) implies that the inequality in (35) must be reversed. This is also valid by the monotonicity of its right-hand side in $y$.

Summarizing this argument, the function $\tau\left(y_{1}\right)$ constructed on $\left[R,(1+R)^{2}-1\right]$ by using $(34)$, from $\tau\left(y_{0}\right)$ on $(0, R)$, satisfies all of the requirements of $(26)$.

The function $\tau(\cdot)$ inherits the necessary property (32), as can be seen by differentiating (34) with respect to $y_{1}$, obtaining

$$
\tau^{\prime}\left(y_{1}\right)=1-\frac{1+R(1-t)}{1+R}\left[1-\tau^{\prime}\left(y_{0}\right)\right],
$$

which is clearly between 0 and 1 because $0<\tau^{\prime}\left(y_{0}\right)<1$. Repeating this procedure in each interval $\left(x_{i}, x_{i+1}\right), \tau(\cdot)$ has the required property throughout its range. (Q.E.D.)

Using the construction employed in the proof of proposition 4, we may study whether the optimal tax is progressive in the amount of the gain. Because marginal tax rates at any particular point are unconstrained, this question is analyzed in terms of whether the average tax increases or decreases as we move from $x_{i}$ to $x_{i+1}$-the only points the tax is determined precisely. Using (30) we compute straightforwardly that

$$
\frac{\tau\left(x_{i+1}\right)-\tau\left(x_{i}\right)}{x_{i+1}-x_{i}}=t+\frac{1-t}{1+R}\left\{1-\left[\frac{1+R(1-t)}{1+R}\right]^{i}\right\} \text {. }
$$


Thus the "marginal" tax paid when the gain increases from $x_{i}$ to $x_{i+1}$ is an increasing function of $i$, which is always between $t$ and $(1+t R) /$ $(1+R)$.

\section{Second-best Taxation at a Uniform Rate}

Because of its simplicity, a linear tax rate that is independent of the holding period is widely used and characterizes current practice as far as long-term capital gains are concerned. As shown above, the lock-in effect will always be present under this system. That is, $\hat{r}_{2}\left(r_{1}\right)$, which characterizes individuals' holding rules, will be a decreasing function of $r_{1}$, given by (7).

We now analyze how the capital-gains rate $t^{\prime}$ should be set so as to maximize the social objective (4). Differentiating (4) with respect to $t^{\prime}$ we have the first-order condition:

$$
\int_{r_{1}}\left(1+r_{1}\right)\left[\hat{r}_{2}\left(r_{1}\right)-R\right] f\left[r_{1}, \hat{r}_{2}\left(r_{1}\right)\right] \frac{d \hat{r}_{2}\left(r_{1}\right)}{d t^{\prime}} d r_{1}=0 .
$$

Using (7) this can be rewritten as

$$
\int_{r_{1}} \frac{(1-t)-\left(1-t^{\prime}\right)\left(1+t r_{1}\right)}{\left(1+r_{1}\right)} f\left[r_{1}, \hat{r}_{2}\left(r_{1}\right)\right] d r_{1}=0 .
$$

If $r_{1}>0$ with probability one, then (39) implies that $t^{\prime}>t$. When the variance of $r_{1}$ is low, an approximation to the optimum is given by

$$
t^{\prime} \approx t\left(\frac{1+E r_{1}}{1+t E r_{1}}\right) \text {. }
$$

This is explained as follows. If $t^{\prime}=t$, then $f_{2}\left(r_{1}\right)<R$ for all $r_{1}>0$, because any investor who had a gain in period one will profit from postponing the tax. By increasing $t^{\prime}$ above this level we favor the alternative asset for individuals with low values of $r_{1}$. In order to strike a balance, with some risky assets sold when $r_{2}$ is too high and some when $r_{2}$ is too low, this policy should be pursued.

\section{Continuous Time Model}

It would be important to generalize the results of the previous section to dynamic situations more complex than the simple two-period structure we have studied thus far. The two-period model eliminates two effects that are present when more realistic considerations are introduced. First, the optimal decision rules, both socially and individually, for holding or selling the asset at any date $s$ cannot be written as functions of $r_{s}$ and the predetermined Jata. Holding the asset may be optimal even when $r_{s}$ is 
low, provided future expected gains are sufficiently high. Second, multiperiod models may entail the possibility of improved information and sequential decision rules which are irrelevant when the horizon consists of only one date beyond the present.

A full treatment of these issues is beyond the scope of this paper. We have, however, analyzed an example in a continuous time model with special properties that rule out the two complexities mentioned above. By taking a family of patterns of returns over time that are all decreasing and known with certainty by the holder of the asset at the initial date, we rule out the effects of learning and can calculate the optimal selling time by a myopic rule.

Returns per unit investment at instant $s$ are given by

$$
r(s)=A e^{-\rho_{s}},
$$

where the parameters $A$ and $\rho$ are known by the holder of the asset at $s=0$ but are unknown to the tax authority. Following the structure of the previous section, the tax authority learns the accumulated capital gain at the date of sale. The total value of the returns on the asset up to date $T$ is

$$
V(T)=\int_{0}^{T} r(s) d s=\frac{A}{\rho}\left(1-e^{-\rho T}\right) .
$$

In the most general case, tax liability can depend on both $T$ and $V(T)$ according to $\tau(T, V(T))$.

The investor chooses his date of sale to maximize the net of tax present value of the asset (returns plus principal, 1) discounting at the net rate of return available on the alternative (safe) asset (which is taxed continually), $R(1-t)$. Thus his problem is

$$
\max _{T}\left\{1+\frac{A}{\rho}\left(1-e^{-\rho T}\right)-\tau\left(T, \frac{A}{\rho}\left(1-e^{-\rho T}\right)\right)\right\} e^{-R(1-t) T} .
$$

Assuming that $\tau(T, 0)=0$ for all $T$; the optimal date of sale will be positive only if $A>R$. To avoid corner-solution problems, which can easily be handled with some complexity of notation, we assume that $A>R$ with probability one.

The optimal holding period $T^{*}$ solves

$$
\begin{aligned}
0=\left(A e^{-\rho T^{*}}-\frac{\partial \tau}{\partial T}-\frac{\partial \tau}{\partial V} A e^{-\rho T^{*}}\right) \\
-\left[1+\frac{A}{\rho}\left(1-e^{-\rho T^{*}}\right)-\tau\right] R(1-t)
\end{aligned}
$$

where $\tau=\tau\left(T^{*},(A / \rho)\left(1-e^{-\rho T *}\right)\right)$.

The planner's problem is to choose a function $\tau(\cdot, \cdot)$ such that the 
solution to (44) maximizes the social present value of the asset discounted at the untaxed rate of return $R$ :

$$
A e^{-\rho T^{*}}=R \text {. }
$$

Thus the condition for an optimal tax function can be obtained by substituting (45) into (44), obtaining

$$
0=\left(R-\frac{\partial \tau}{\partial T}-\frac{\partial \tau}{\partial V} R\right)-(1+V-\tau) R(1-t) .
$$

Equation (46) is a partial differential equation in $\tau$. We investigate the existence of solutions for the two special types of tax functions corresponding to those of the two-period model: (a) linear taxation at variable rate: $\tau(T, V)=\alpha(T) V$, and $(b)$ nonlinear taxation, independent of the holding period: $\tau(T, V)=\tau(V)$. Assuming that $\tau(T, V)=\alpha(T) V$, equation (46) becomes

$$
\frac{d \alpha}{d T}+\alpha\left\{\frac{R[1-(1-t) V]}{V}\right\}+R\left[\frac{(1-t)(1+V)-1}{V}\right]=0 .
$$

If an optimal tax function of this form exists then (47) can be solved for a function $\alpha(T)$ independent of $V$. Holding $V$ constant, we see that the general form of a solution to (47) is

$$
\alpha(T)=C e^{-\left\{\frac{R(1-(1-t) V}{V}\right\}_{r}}+\frac{1-(1-t)(1+V)}{[1-(1-t) V]},
$$

where $C$ is an arbitrary constant. Since there is no boundary condition on $\alpha, C$ can, in principle, depend on $V$. But clearly there is no function $C(V)$ such that $\alpha(T)$ given by (48) becomes independent of $V$.

Now assuming $\tau(T, V)=\tau(V)$, we have from (46)

$$
\frac{d \tau}{d V}-\tau(1-t)+(1-t)(1+V)-1=0
$$

the general solution of which is

$$
\tau(V)=C e^{(1-t) V}+V+1 \text {. }
$$

The boundary condition $\tau(T, 0)=0$ for all $T$ implies $C=-1$ so that the optimal nonlinear tax function is given by

$$
\tau(V)=V+1-e^{(1-\imath) V} .
$$

The form of (51) displays some peculiarities. Taxation is regressive in the amount of the gain. Moreover, for $V$ sufficiently large, marginal and even total taxes are negative. This may be a consequence of the special form for the returns but perhaps belies some more general difficulties in multiperiod models. We hope to explore this in future work. 


\section{Private willingness to Hold Risky versus Safe Assets}

Up to now we have regarded the supply of risky projects as fixed and have not investigated the willingness of individuals to hold this asset. More generally one can assume that the distribution of the rate of return on risky assets depends on the proportion of capital invested there. In equilibrium, the rates of return will be equalized, and a social tax policy must take this margin into account. To explore the full implications of second-best analysis in this regard is beyond the scope of this paper. The optimal taxes would depend on the exact way in which the joint distribution of rates of return shifts when the aggregate portfolio is varied.

In the present paper we can consider only the direction of the bias, toward or away from the risky asset, given that it exists in inelastic supply at the socially optimal level. We assume that $r_{1}$ and $r_{2}$ are independently, identically distributed and that their variance is small. We will consider two situations: the first best, as attained by linear taxes, and the second best, when only linear taxes independent of the holding period are allowed. We will show that in the first case a bias is created in favor of the risky asset, while the second case entails a bias in the opposite direction.

\section{First Best}

At the first best, the two assets have the same expected return and the holding rule for the risky asset is $f_{2} \equiv R$. Thus,

$$
\begin{aligned}
\int_{r_{1}} \int_{r_{2}>R}\left(1+r_{1}\right)\left(1+r_{2}\right) f\left(r_{1}\right) f\left(r_{2}\right) d r_{2} d r_{1} \\
+\int_{r_{1}} \int_{r_{2}<R}\left(1+r_{1}\right)(1+R) f\left(r_{1}\right) f\left(r_{2}\right) d r_{2} d r_{1}=(1+R)^{2} .
\end{aligned}
$$

We want to determine which asset is more attractive to an investor at this social optimum. We will show that the risky asset has a higher expected net yield, when the variance of $r_{t}, t=1,2$ is sufficiently small. That is,

$$
\begin{gathered}
\int_{r_{1}} \int_{r_{2}>R}\left[\left(1+r_{1}\right)\left(1+r_{2}\right)-t\left(r_{1}+r_{2}+r_{1} r_{2}\right)\right] f\left(r_{1}\right) f\left(r_{2}\right) d r_{2} d r_{1} \\
+\int_{r_{1}} \int_{r_{2}<R}\left\{1+r_{1}\left[1-\frac{t}{1+R(1-t)}\right]\right\}[1+R(1-t)] f\left(r_{1}\right) f\left(r_{2}\right) d r_{2} d r_{1} \\
>[1+R(1-t)]^{2} .
\end{gathered}
$$

Using (52), (53) becomes

$$
\begin{aligned}
\int_{r_{1}} r_{1} f\left(r_{1}\right) d r_{1} & +\left[\int_{r_{1}}\left(1+r_{1}\right) f\left(r_{1}\right) d r_{1}\right] \\
& \cdot \int_{r_{2}} \max \left(r_{2}, R\right) f\left(r_{2}\right) d r_{2}<2 R+R^{2}+R^{2}(1-t) .
\end{aligned}
$$


By virtue of the social optimum condition it is clear that

$$
\int_{r_{1}} r_{1} f\left(r_{1}\right) d r_{1}<R
$$

If the variance of $r_{2}$ is sufficiently small,

$$
\int_{r_{2}} \max \left(r_{2}, R\right) f\left(r_{2}\right) d r_{2}-R
$$

is negligible. In this casc, (53) follows directly.

\section{Second Best}

The social optimum when the variance of $r_{1}$ is small occurs when $E r_{1} \approx R$. In this case the second-best formula $(40)$ is

$$
t^{\prime} \approx t\left(\frac{1+R}{1+t R}\right)
$$

Clearly there is a bias away from the capital asset, since it is virtually identical in its gross return but is taxed at a higher rate.

\section{Conclusions}

We have explored the possibilities for decentralizing the socially optimal investment policy regarding the continuation or termination of assets' returns that can vary over time, when the tax authorities' information is highly limited. The analysis assumed that the supply of such assets is fixed. In this context the first best can be attained in a variety of ways. More generally, as was shown in the last section, the optimal policy will create a divergence between private and social returns to investment in alternative classes of assets. The overall optimal policy is necessarily of a second-best nature. We hope, nevertheless, that the results derived here will shed light on these more complex situations.

\section{References}

David, Martin H. Altemative Approaches to Capital-Gains Taxation. Washington: Brookings Inst., 1968.

Vickrey, William S. Agenda for Progressive Taxation. New York: Ronald, 1947. 